\title{
A participação da sociedade civil na esfera pública, direitos humanos e empresas: uma abordagem emoldurada com conceitos habermasianos.
}

\author{
Luísa Nascimento Bustillo* \\ Dr. José Marcos Miné Vanzella**
}

Resumo: O presente artigo, com metodologia de pesquisa jurídica, bibliográfica, interdisciplinar e documental tem por objetivo analisar o alcance das demandas emanadas pela sociedade civil, acerca da regulamentação dos efeitos horizontais dos direitos humanos emoldurando a discussão com os conceitos habermasianos de sociedade civil, esfera pública e circulação de poder. Aborda a evolução dos direitos humanos e a sua relação com a dignidade da pessoa humana, bem como o papel do Estado. Apresenta documentos emanados de associações, ONGs e de autoria das Nações Unidas que postulam a responsabilização direita de empresas e particulares por quaisquer violações.

Palavras-chave: direitos humanos e empresas, sociedade civil, Esfera pública, ONU, Habermas.

\section{THE PARTICIPATION OF CIVIL SOCIETY IN THE PUBLIC SPHERE, HUMAN RIGHTS AND COMPANIES: AN FRAMED APPROACH WITH HABERMASIAN CONCEPTS.}

\begin{abstract}
The present article, by legal, bibliographic, interdisciplinary and documentary methodology of research, aims to analyze the scope of requests emanated of civil society, regarding the regulation of the horizontal effects of human rights, framing the discussion with the Habermasian concepts of civil society, public sphere and circulation of power. It addresses the evolution of human rights and its relation to the dignity of the human person, as well as the role of the State. It presents documents emanating from associations, NGOs and the United Nations that postulate the right accountability of companies and individuals for any violations.
\end{abstract}

Keywords: human rights and business, civil society, public sphere, UN, Habermas.

\footnotetext{
* Mestranda em Direito pelo Centro Universitário Salesiano de São Paulo - U.E. Lorena (SP). E-mail: luisanascimentob@gmail.com

** Doutor em Filosofia pela Universidade Gama Filho (Rio de Janeiro), Professor e Pesquisador no Programa de Mestrado em Direito do Centro Unisal - U.E. Lorena (SP) / Professor da Faculdade Dehoniana (FADE) E-Mail: enimine@gmail.com
} 


\section{Introdução}

O presente artigo com metodologia de pesquisa jurídica, bibliográfica, interdisciplinar e documental tem como finalidade contribuir com considerações sobre o desenvolvimento da pauta regulamentadora de direitos humanos e empresas no nível político internacional, emolduradas pelos conceitos habermasianos de sociedade civil e esfera pública.

Primeiramente, procura realizar uma abordagem acerca da evolução dos direitos humanos, especialmente, no contexto pós-segunda guerra mundial, analisando qual é a vinculação destes ao princípio da dignidade humana (item 1). Esta menção é importante para se discutir abusos de entes particulares, como são as empresas, pois é necessário entender o cerne da proteção nas atuais ordens internas e externas. Ainda, é necessário destacar como a reestruturação do Direito Internacional dos direitos humanos em torno da dignidade da pessoa humana teve grandes consequências tanto na reorganização dos sistemas de proteção regionais e universais, quanto nas ordens jurídicas estatais, mais especificamente no direito constitucional brasileiro.

Para entender as pressões exercidas com relação à pauta acerca da regulamentação dos direitos humanos, é necessário, também, que se explicite o papel do Estado diante da evolução dos direitos humanos. Para isso, realizar-se-á uma pequena síntese de tal desenvolvimento (item 2). Com isso em vista, ressalta-se que o Estado, apesar de ter sido o principal violador de direitos humanos durante um longo período, hoje não pode mais ser considerado como o exclusivo. Deve-se considerar a questão das circunstanciais em que entes particulares, notadamente, as empresas privadas, devem ser considerados como violadores potenciais.

Dessa maneira, o tema proposto contribui para a consideração dos efeitos horizontais dos direitos humanos, ou seja, os seus efeitos entre particulares, cerne da demanda para que seja estabelecido, no contexto da política internacional, a responsabilização direita de empresas e particulares que atentem contra tais direitos.

Frise-se, entretanto, que para a concretização de qualquer mudança, a pauta se submete a um modelo de circulação de poder político que tem origens na disputa por influência na esfera pública habermasiana, se desenvolve em sadias discussões até bater às portas do sistema político de fato, conforme desenha Habermas (2010) (item 3).

Assim, o presente artigo tem por objetivo analisar o alcance das demandas emanadas pela sociedade civil, exemplificadas por documentos enviados a organizações internacionais, acerca da regulamentação dos efeitos horizontais dos direitos humanos, tendo em consideração 
tal emolduração habermansiana, ilustrando-a pela indicação de como os pleitos trafegam pelas organizações internacionais e pelas tentativas de consenso realizadas no tema, consolidadas, por sua vez, em documentos internacionais de autoria das Nações Unidas.

\section{Direitos Humanos e a vinculação à dignidade humana: uma contextualização}

Primeiramente, para discussão que aqui se propõe ${ }^{1}$, é necessário expor a evolução dos direitos humanos e a sua vinculação ao Princípio da Dignidade da Pessoa Humana, a aceitação desta pela sociedade internacional e as consequências posteriores.

Conforme já expresso em seu primeiro artigo, no inciso III, mais especificamente, a Constituição Federal brasileira vigente teve como preocupação internalizar o Direito Internacional dos Direitos Humanos, assumindo o Princípio da Dignidade da Pessoa Humana como fundamento do Estado Democrático de Direito, que ali era instituído (BRASIL). Isso reflete, explicitamente, um movimento realizado igualmente em nível internacional após a Segunda Guerra Mundial.

Após 1945, há a clara reafirmação de uma norma fundamental na sociedade internacional, que se reflete em movimentos constitucionais posteriores e que possui como matriz a proteção da dignidade da pessoa humana. O processo pode ser visto por meio da positivação da proteção da dignidade humana em textos universais, cunhados pela ONU, (e posteriormente por cartas constitucionais). Em consonância, Jürgen Habermas (2012, p. 9) aponta que somente após a segunda grande guerra o conceito desta dignidade em sua atual significação passou a figurar em codificações.

Conforme Richard B. Bilder (apud PIOVESAN, 2012, p. 62) foi em 1945, após reveladas as violações de direitos humanos impetradas pelo regime nazista que se estabeleceu a promoção dos direitos humanos e das liberdades fundamentais como um dos principais objetivos da Organização das Nações Unidas, possibilitando a emersão de diversos direitos hoje consolidados no Direito Internacional dos Direitos Humanos.

Conceitos como moral, ética e justiça, antes pertencentes às disciplinas da sociologia e filosofia, foram de novo associados ao mundo jurídico, permitindo a discussão da legalidade

\footnotetext{
${ }^{1}$ Isso porque não é possível falar em proteção dos direitos humanos e da dignidade da pessoa humana contra abusos de particulares sem conceituá-los na ordem internacional, mencionando a importância do assunto nas atuais ordens internas e externas.
} 
e da legitimidade ligada aos fundamentos democráticos do Estado de direito. Verifica-se uma maior preocupação em nortear o sistema jurídico em princípios, que adquirem força normativa.

Habermas (2012, p. 10-11) afirma, a partir de uma abordagem histórico sistemática, que mesmo de modo implícito, sempre houve um vínculo conceitual entre os conceitos de direitos humanos e de dignidade humana (apesar do “surgimento” tardio deste último).

O referido autor (2012), inicialmente, aponta que a gênese dos direitos humanos lhe parece muito clara: são diretamente derivado da arbitrariedade, opressão e humilhação (violações), como oposição a estas. Assim, o contexto do pós-guerra foi essencial para se pensar a positivação do conceito da dignidade da pessoa humana nos textos norteadores dos sistemas jurídicos internacionais e nacionais. Habermas (2012) relata que as condições históricas apenas ressaltaram, nos direitos humanos, o que ali já encontrava morada: a substância normativa da dignidade humana presente em todo ser humano de maneira igual.

Sintetizando a relação entre direitos humanos a dignidade humana, Habermas afirma que esta é a “fonte moral da qual os direitos fundamentais extraem seu conteúdo” (2012, p. 11), bem como que esta possui papel catalisador na composição destes “a partir da moral racional e da forma do direito” (2012, p. 12). Assim, o autor afirma que a dignidade humana é a ponte pela qual “o conteúdo igualitário universalista da moral é importado ao direito” (2012, p. 17), direito este positivo e democrático, emergido de uma ordem política fundamentada nos direitos humanos (até, porque, a posteriori, percebemos que somente nesta ordem, cidadãos conseguem usufruir dos direitos protetivos da dignidade humana).

Em conclusão, acerca da intersecção tratada, é Habermas expõe: “...os direitos humanos delimitam a parte de uma moral esclarecia que pode ser traduzida como medium do direito coercitivo e ter realidade política efetiva” (2012, p. 18) apontando para a efetividade de direitos fundamentais, institucionalizados. Os direitos humanos seriam, portanto, a síntese da moral interiorizada (consciência subjetiva e fundamentada racionalmente) adicionado ao direito coercitivo, realizada por meio da dignidade humana.

Habermas defende ainda que os direitos humanos protegem uma dignidade humana que extrai sua conotação de autorrespeito e reconhecimento social do status de uma cidadania democrática situada no espaço e no tempo (2012).

Assim, diante disso, as ordens nacionais também reconheceram e interiorizaram o princípio da dignidade humana como matriz dos novos sistemas constitucionais. Ocorreu, em muitos países, uma reestruturação do Direito Constitucional, que Flavia Piovesan expressa 
como sendo o surgimento de uma nova topografia (2012, p. 90), absolutamente necessária para reafirmar a supremacia do Princípio da Dignidade da Pessoa Humana e incluir, no caso da constituição brasileira em vigência, diversos direitos fundamentais, liberdades e garantias, que expressam um sistema principiológico que não só orientam como são vinculantes para todo o ordenamento jurídico nacional.

Esta “nova topografia” acima retratada é de uma importância, pois, segundo Habermas, apenas é possível usufruir dos direitos que protegem a dignidade humana quando se consegue "estabelecer e manter em comum uma ordem política fundamentada nos direitos humanos”. (HABERMAS, 2012, p. 24). Entende-se, pois os direitos humanos vinculados a sua fonte moral a dignidade humana e positivados a partir de lutas contra suas violações e efetivados a partir da manutenção de ordens jurídicas das comunidades políticas.

\section{O papel estatal diante da evolução dos direitos fundamentais: um paralelo} entre estados e empresas

É necessário, também, explicitar o papel do Estado diante da evolução dos direitos fundamentais. Assim sendo, é imprescindível realizar uma pequena síntese de caráter histórico, que se inicia com a Revolução Francesa, que se ergueu frente ao Absolutismo, visando a determinação de limites à atuação estatal, de modo a diminuir os abusos e privilégios monárquicos. O movimento evidenciou, portanto, a liberdade e a abstenção estatal, promovendo os chamados direitos de primeira geração, ou dimensão, como esclarecido por Bobbio (2004), que consistem nos direitos civis e políticos.

Após a Primeira Guerra Mundial, observa-se o nascimento de um discurso social, que ganhou força. Neste ponto, Flávia Piovesan explicita que com a emergência dos direitos à prestação social, o pleiteado direito à abstenção do Estado converte-se em direito à atuação estatal, sendo o Estado visto como agente de processos transformadores. (2012, p. 206). Diante deste contexto, ganham notoriedade os direitos econômicos e sociais, ou direitos de segunda geração, ou dimensão, ainda na concepção exposta por Bobbio (2004). Estes, possuem como escopo a tutela da isonomia substancial, objetivando a concretização dos direitos humanos, perpassado pela máxima da dignidade da pessoa humana, objetivando criar condições socialmente justas para seus cidadãos.

A mencionada dicotomia entre direitos civis e políticos e direitos sociais não permanece nos moldes apresentados por muito tempo, sendo fragilizada no período que segue à Segunda Guerra mundial com a aceitação do fato de que os direitos humanos são uma unidade 
absolutamente completa, indivisível e interdependente, sendo impossível “separá-los”. Neste ponto, Habermas (2012) aduz, diversas vezes, que os direitos fundamentais apenas serão capazes de resgatar, em âmbito político, a promessa de respeito à tal dignidade se houver uma interação de modo igualitária em todas as suas categorias, o que fundamenta também a indivisibilidade dos direitos em questão.

Henkin esclarece o explicitado sobre essas duas dimensões de direitos, quando menciona que os direitos fundamentais requerem limitações sobre interferências por parte dos governos nos direitos civis e políticos e, ao mesmo tempo, necessitam de obrigações de cunho positivo destes mesmos governos (apud PIOVESAN, 2012 p. 209).

José Afonso da Silva, em consonância, explica o escopo dos direitos sociais:

(...) os direitos sociais, como dimensão dos direitos fundamentais do homem, são prestações positivas proporcionadas pelo Estado direta ou indiretamente, enunciadas em normas constitucionais, que possibilitam melhores condições de vida aos mais fracos, direitos que tendem a realizar a igualização de situações sociais desiguais. São, portanto, direitos que se ligam ao direito de igualdade. Valem como pressupostos do gozo dos direitos individuais na medida em que criam condições materiais mais propícias ao auferimento da igualdade real, o que, por sua vez, proporciona condição mais compatível com o exercício da liberdade. (SILVA, 2011, p. 286).

Por conta desta essência própria destes direitos, que demandam prestações positivas, Aldo Caliari (2009) leciona que a proteção destes necessita um Estado que seja de fato ativo na política econômica e social, que não seja mínimo para fazer regulamentações e fiscalizações, especialmente, no que tange ao setor privado. Ou seja, para a realização de direitos humanos, tanto de cunho civil e político e notadamente de cunho social, é necessário um Estado com capacidade de frear um capitalismo cruel, em nome da proteção do bem-estar social de seus cidadãos, como o faz o denominado Welfare State.

Esta expressão é referente a um modelo estatal que visa garantir o bem-estar dos cidadãos, com políticas públicas para a efetivação dos direitos sociais, sempre tendo como máxima a proteção e a promoção da dignidade da pessoa humana. É um gênero estatal com raízes intrincadas na social democracia, com instituições que não rechaçam a intervenção, primando por uma política redistributiva e uma justiça social a fim de amenizar desigualdades, acirradas com o sistema capitalista.

No constitucionalismo moderno, portanto, é dado que do Estado, no que concerne a proteção e a promoção de direitos fundamentais, se requer também uma intervenção positiva, 
para que os direitos e garantias fundamentais se efetivem. E, em tal cenário, a atividade de pessoas privadas, assim como a regulamentação estatal com relação à estas, tomam proporções importantes.

Com isso em vista, é necessário destacar que o Estado, apesar de ter sido o principal violador de direitos humanos, não pode mais ser considerado como único. Os entes particulares, notadamente, as empresas privadas, igualmente, podem ser violadoras em potencial. Isso porque, com a industrialização, a globalização, a internacionalização do comércio, houve também uma expansão do capital e proliferação de empresas transnacionais. Consequentemente, houve o crescimento do chamado capital transfronteiriço (GASPAR e BUSTILLO, 2013). Diante desse contexto, aumentaram os posicionamentos políticos e econômicos de cunho mais liberal, que acabam por induzir uma diminuição da atuação estatal, tendência vista na América Latina no fim do século XX e outras regiões, especialmente do sul global. Diego Valadés resume que o Estado, de fato, representava uma ameaça para a liberdade de seus jurisdicionados, contudo, o autor frisa que, hoje, os indivíduos estão sob “fogo duplo”: do Estado e de outros particulares, tendo em vista que poder destes "se dilatou quase na mesma proporção em que o poderio público diminuiu” (2011, p. 440, tradução nossa).

Este quadro torna-se extremamente preocupante quando se leva em conta que empresas não possuem as obrigações positivas impostas ao Estado pela pequena evolução histórica acima narrada. Também, apesar de serem potenciais violadoras, não se submetem diretamente aos sistemas de proteção de direitos humanos.

Atualmente, a problemática pode ser ilustrada por diversos casos. Em documento denominado Access to Justice: Human Rights Abuses Involving Corporations- Brazil (Summary Executive),a Comissão Internacional de Juristas (CIJ, 2011) indica 13 casos de violações de direitos fundamentais por empresas que ocorreram no Brasil. Há outros exemplos recentes latino-americanos, como o caso do Povo de Indígena Kichwa de Sarayaku versus Equador, caso analisado pela corte interamericana, ${ }^{2}$ e o desastre ambiental causado pela Chevron, no mesmo país. Neste último caso, em particular, é necessário apontar que mesmo

\footnotetext{
${ }^{2} \mathrm{O}$ caso versa sobre a outorga (pelo Estado) de a uma empresa privada para realizar atividades de exploração de petróleo no território do Povo Indígena Kichwa de Sarayaku, sem qualquer consulta prévia destes. A corte interamericana limitou-se em responsabilizar o Estado por danos causados, estabelecendo reparações e recomendações, (incluindo neutralizar, desativar e retirar a substância explosiva, pentolite, deixada pela empresa privada ali extraia petróleo). Sanções diretas ou considerações para empresas não são feitas - estas podem serem realizadas internamente pelo país onde a violação ocorreu (GASPAR e BUSTILLO, 2013). Para mais informações acerca, consultar a íntegra do caso em: http://www.corteidh.or.cr/docs/casos/articulos/seriec_245_esp.pdf
} 
condenada no âmbito interno, a Chevron jamais cumpriu a condenação da corte suprema equatoriana (quase U\$ 9,5bi), retirando todos os bens do país e tornando impossível uma execução. Ainda, questão acerca da possiblidade de imposição de obrigações positivas quanto aos direitos humanos ganha notoriedade quando se constata que o cenário mundial está marcado por empresas multinacionais que por vezes abusam de recursos naturais do local onde instaladas (por vezes no sul global ou na Ásia), mas mantêm o capital financeiro especulativo em suas sedes (em países desenvolvidos).

Ainda nesse sentido, Habermas explica que:

Hoje em dia, assistimos a uma privatização cada vez mais ampla de realizações que até agora, por boas razões, eram reservadas ao Estado nacional. Com a transmissão para empreendedores privados, afrouxam-se os laços que prendiam tais serviços e produções ao texto de uma constituição. Isso é tanto mais arriscado quanto mais a privatização atingir esferas nucleares do poder da soberania - segurança pública, forças armadas, sistema penal, ou a geração de energia. O legislador democrático, no entanto, ainda é submetido, além disso, a um outro tipo de despontecialização, a partir do momento em que a globalização da economia, desejada politicamente, passou a desenvolver uma dinâmica própria. Porquanto agora, os processos sociais que são relevantes para a garantia da liberdade e da segurança do direito, para a justiça distributiva e para a convivência com igualdade de direitos subtraem-se ao controle político, numa proporção cada vez maior. Agudiza-se, em todo caso, a assimetria entre a responsabilidade atribuída ao Estado democrático e o espaço real de sua influência. (1997, p. 370).

Diante do desequilíbrio do poder exposto, e da ausência de diligências de empresas privadas com os direitos humanos (seja para com a “não violação”, seja para com obrigações positivas) é necessário considerar o efeito horizontal destes direitos.

Virgílio Afonso da Silva, ao discutir o mencionado efeito, expressa ser o primeiro passo para superar a visão tradicional do Estado como único violador dos direitos humanos, a determinação de um paralelo entre este e as grandes corporações (2011, p.53). Nesse tocante, esclarece Bloomer, mencionando Henkin, que:

A maioria dos tratados internacionais de direitos humanos é destinada aos Estados. No entanto, o preâmbulo da Declaração Universal dos Direitos Humanos exorta "todos os indivíduos e todos os órgãos da sociedade" a promover e respeitar os direitos humanos, o que, segundo o professor Louis Henkin, um relevante erudito de direito internacional, "não exclui ninguém, nenhuma empresa, nenhum mercado, nenhum ciberespaço". (HENKIN, 1999, p. 25 apud BLOOMER, 2014, p. 120, grifo nosso) 
Portanto, diante de uma acelerada globalização e expansão do mercado econômico, cresce a demanda na sociedade civil em âmbito estatal e internacional para, no contexto da política e dos sistemas de proteção, que seja estabelecido que além do Estado, empresas e particulares devem ser diretamente responsabilizados por violações, bem como a estes também se atribuam obrigações positivas, ou seja, cresce a demanda pela regulamentação do assunto, que se manifesta até mesmo em nível internacional, já que tais direitos são tutelados internacionalmente. Em consonância, leciona Jürgen Habermas: “com a desregulamentação e o desconfinamento dos fluxos de informação e de comércio internacionais em muitas outras dimensões surge uma necessidade de regulamentação, a qual é captada e processada por redes e organizações transnacionais” (2007, p. 370).

Contudo, não é fácil concretizar tais propostas de regulamentação: elas se submetem a um modelo de circulação do poder político que se inicia a partir da esfera pública num caminho nem sempre fácil, até bater às portas do sistema político, das esferas de decisão, assim como no modelo de habermasiano (2010) para a teoria democrática do Estado de direito.

\section{O modelo habermasiano de esfera pública, a participação da sociedade civil e} as decisões no sistema político: uma ilustração pelo campo de regulação de Direitos Humanos e empresas

Habermas explica, no âmbito estatal, o conceito de esfera pública, como sendo "uma rede adequada para a comunicação de conteúdos, tomadas de posição e opiniões; nela os fluxos comunicacionais são filtrados e sintetizados, a ponto de se condensarem em opiniões públicas enfeixadas em temas específicos” (2010, p. 92). Nela, portanto, se iniciam e se determinam os tópicos importantes a serem levados para esfera política, e transformarem-se em decisões.

A esfera em questão, igualmente, se reproduz através do agir comunicativo: “implicando apenas o domínio de uma linguagem natural; ela está em sintonia com a compreensibilidade geral da prática comunicativa cotidiana. ” (2010, p. 92). Com uma abertura ao mundo da vida, extrai das experiências privadas os tópicos de interesse, de discussão, e deixa à cargo do sistema político qualquer elaboração mais especializada, de modo a manter o diálogo acessível e democrático aos indivíduos. Ou seja, a função da esfera pública habermasiana é majoritariamente “captar e tematizar os problemas da sociedade como um todo” (2010, p. 97).

Nessa esfera, eventualmente há a organização das informações e argumentos em opiniões enfeixadas, e dependendo do assentimento que estas recebem, transformam-se em 
opinião pública (HABERMAS, 1997, p. 94). Habermas diferencia o conceito de opinião pública do agregado de opiniões individuais resultante de pesquisas (eleitorais, por exemplo). Por opinião pública, entende-se uma congruência de opiniões informadas e formadas num espaço público mobilizado. Ele esclarece, ainda, que na referida esfera, luta-se por influência:

pois ela se forma nessa esfera. Nessa luta não se aplica somente a influência política já adquirida (de funcionários comprovados, de partidos estabelecidos ou de grupos conhecidos como o Greenpeace, a a Anistia Internacional, etc.), mas também o prestígio de grupos de pessoas e de especialistas que conquistaram sua influência através de esferas públicas especiais (Por exemplo, a autoridade de membros da igreja, a notoriedade de literatos e cientistas (...) (1997, p. 95).

Levando-se em conta a multiplicidade de atores e pretensões que circulam por tal espaço (frise-se que Habermas aponta, ainda que há “aproveitadores” no cenário), e do ponto de vista de defensores de certas pautas, levar problematizações ao sistema político não é tarefa simples. Neves e Lubenow sintetizam o processo com clareza:

“(...) está presente uma periferia formada por associações e organizações formadoras de opinião e capazes de gerar influência pública. Essas associações são a infraestrutura civil de uma esfera pública que, em alguns casos, tentam influir na formulação e na implantação de políticas” (NEVES e LUBENOW, 2008, p. 253)

As mencionadas associações podem ser ilustradas por movimentos sociais (feministas, pacifistas, etc.) e outras mais elementares como associações de moradores, associação de pais, etc. Logo, salta aos olhos a relação desta esfera e da sociedade civil. O núcleo da sociedade civil é composto por "associações, organizações e movimentos emergentes mais ou menos espontâneos” (NEVES e LUBENOW, 2008, p. 257) e frise-se: não estatais, não econômicos, que "institucionaliza os discursos capazes de solucionar problemas, transformando-os em questões de interesse geral no quadro de esferas pública”. (HABERMAS 2010, p. 99). Assim, essas organizações retiram do mundo da vida, e da vida privada, os temas e problemas relevantes, os condensam e os levam para esfera pública política, já com certa amplificação.

Apesar de Habermas desenvolver estes conceitos analisando o âmbito interno de uma democracia do Estado de direito, é possível fazer uma extensão ao nível da política internacional. Acerca do direito internacional, Habermas expõe que uma herança kantiana 
permitiu projetar uma “constituição cidadã” para um plano global, de modo que se franqueasse o espaço para uma constitucionalização dos direitos das gentes ((HABERMAS, 2007, p. 350). Isso refletiu diretamente no cenário internacional:

A grandiosa inovação de tal conceitualização, que ultrapassou, em muito, as condições existentes à época, reside principalmente na reformulação do direito internacional tido como um Direito de Estados: ele passou a ser entendido como um "direito de cidadãos do mundo" (...). Estes passam a gozar do status de sujeitos de direito, isto é, não são mais, apenas, “cidadãos” (Bürger) de um Estado nacional, mas também membros de uma sociedade mundial estruturada de forma política. (HABERMAS, 2007, p. 350)

Porém, o direito internacional se redesenhou para um modelo jurídico de cooperação entre Estados em redes multilaterais ou sistemas de negociação transnacionais sem o caráter estatal, dispensando, inclusive a legitimação que, nos estados democráticos, deriva da vontade e da cidadania (HABERMAS, 2007, p. 353). Frise-se, contudo, que a formação da opinião e da vontade política ainda é fator essencial na circulação de poder mesmo em nível internacional para a formação de discussões democráticas e a construção de consenso. Sobre esta atuação, Habermas explica:

A formação da opinião e da vontade da organização mundial deveria, certamente, ser retroligada aos fluxos de comunicação de parlamentos nacionais, estar aberta à participação de organizações não governamentais autorizadas a participar de discussões e ser expostas à observação de uma esfera pública mundial mobilizada. (2007, p. 360).

Habermas, assim, aponta a importância de uma esfera pública mobilizada para a formação da opinião e da vontade em nível internacional, que por sua vez, deve ser nutrida pelos fluxos comunicacionais dos parlamentos, bem como da participação de ONGs. Com esta percepção do direito internacional e suas organizações, ele ressalta a necessidade de uma regulamentação não apenas nacional dos sistemas funcionais, que, apenas poderia ser satisfeita se a arena intermediária fosse ocupada por um número razoável de “jogadores globais”, fortes o suficiente para estruturar coalizões (não-fixas) e equilíbrios de poder (flexíveis) para tal questão e "negociar compromissos obrigatórios que tenham condições de implementação" (HABERMAS, 2007, p. 362).

A demanda, principal, percebida entre os atores perante às organizações internacionais quanto ao tema envolvendo empresas e direitos humanos não difere do exposto acima pelo autor, sendo expressa no desejo de que haja consenso em um instrumento internacional com 
força vinculante às empresas, estabelecendo obrigações positivas para com a realização dos direitos mencionados e sanções em caso de violação.

Para demostrar como tal demanda trafega pelas organizações internacionais, é interessante apontar alguns documentos elaborados nas últimas décadas nesse sentido e alguns outros que expressam tentativas de construção de consenso acerca da temática.

Em 2004, na cidade de São Paulo, ocorreu a 11ª Conferência das Nações Unidas sobre Comércio e Desenvolvimento-UNCTAD ${ }^{3}$ XI, órgão subsidiário da Assembleia Geral da ONU, que trabalha com diversos atores (Estados Nacionais, instituições governamentais, ONGs e setores privados) a fim de promover integração de países em desenvolvimento no mundo econômico, objetivando auxiliar a articulação entre políticas nacionais e internacionais. Realizadas de quadrienalmente, as conferências assumem a função de construir consenso entre governos quanto à economia mundial e às políticas de desenvolvimento, balizando assim a atuação das Nações Unidas. Suas decisões, contudo, não possuem qualquer força vinculativa, servindo como mecanismo de pressão utilizado por e em prol de países em desenvolvimento (GASPAR e BUSTILLO, 2013).

$\mathrm{Na} 11^{\mathrm{a}}$ Conferência[...], foi submetido o documento denominado Declaração do Fórum da sociedade Civil para UNCTAD XI, elaborado por movimentos sociais e outros grupos, com uma série de apontamentos e recomendações acerca do tema proposto. Critica a resolução principal da Conferência por se omitir em relação a abusos de recursos naturais e políticas falhas de partilha, má distribuição do lucro e, ainda, tece uma série de recomendações, dentre as quais que o comércio internacional se submeta à Declaração Universal dos Direitos Humanos e outros instrumentos do direito internacional. Recomenda também que se proíba que multinacionais adotem medidas legais (ou convencionais) contra Estados receptores, devido às políticas públicas em favor do desenvolvimento social.

Assim, a declaração sintetiza uma de suas maiores críticas ao apontar que a democracia passa por um grande processo de desgaste quando governos renunciam o direito de regulação, para obter maior acesso ao mercado, de modo que “(...) Os lucros, então, progressivamente vão para as indústrias e seus donos, ao invés de serem revertidos para países e suas populações” (2004, p.4, tradução nossa).

\footnotetext{
${ }^{3}$ Sigla para United Nations Conference of Trade and Development.
} 
É preciso considerar também que a responsabilização de transnacionais está ligada ao domicílio da empresa: a responsabilização extraterritorial é carente de regulamentação. Em resumo, a declaração expressa a necessidade de legislação vinculativa multilateral responsabilizadora, mesmo que de forma penal, concebida considerando as variáveis peculiaridades espaciais e econômicas, demandando a instalação de instituições multilaterais e legislação internacional, a ser construída em ambientes de consenso internacional tal como a ONU, pautadas pelo bem-estar social, proteção ambiental, dentre outros aspectos, de modo a subordinar políticas comerciais a acordos internacionais, tanto sociais quanto ambientais (2004, p.4).

É possível constatar, que a conferência, como expressa o documento, frisou a urgência da elaboração de um documento internacional de caráter vinculante capaz de proteger direitos fundamentais frente a empresas, estabelecendo punições a quaisquer violações eventualmente perpetradas, assim como aponta a necessidade de preservação do direito estatal de manter sua política econômica de acordo com a sustentabilidade, a saúde e o desenvolvimento social em geral (GASPAR e BUSTILLO, 2013).

Um segundo documento chama atenção no cenário desenhado, denominado Brazilian obligations to address human rights violations perpetrated by companies (2011), submetido pela ONG Conectas Direitos Humanos, juntamente com mais seis instituições, ao Segundo Ciclo de Revisões Universais Periódicas realizado pela ONU. Frise-se que as revisões são, em verdade, um sistema de monitoramento, em sede global, para verificação da concretização e respeito aos direitos humanos pelo Estados-partes.

O documento relata, principalmente, 13 casos de violação de direitos humanos por empresas no país e o comportamento do Estado perante as violações. O relatório em pauta (2011) concluiu que, apesar do país ser signatário de vários instrumentos internacionais de direitos humanos, que poderiam (e deveriam) servir de respaldo protetivo em caso de qualquer abuso, seja este perpetrado por empresas, não há um controle consolidado nessa seara: O estado raramente exerce fiscalização para aferir se as empresas estão ferindo ou não direitos fundamentais.

Assim, aduz que é obrigação estatal garantir, promover e prevenir violações de direitos humanos, assim como investigar e punir tais ocorrências, dentre outras recomendações. O documento enfatiza as obrigações do Estado, não atribuindo muita importância às obrigações 
que as empresas deveriam se ater, mas não deixando de ser um documento que demonstra a participação ativa da sociedade civil (GASPAR e BUSTILLO, 2013).

Iniciativas como as narradas são ilustrativas do modelo habermasiano de esfera pública e poder político, demonstrando com clareza que a sociedade civil, numa esfera pública ainda maior que o âmbito estatal, seleciona sim temas de importância, problemas do mundo da vida e institucionaliza discursos, fazendo-os ecoar na esfera pública e atingir o sistema político para decisões.

E, consoando com o desenho de Harbermas supramencionado, por conta de inciativas como as citadas, o tema envolvendo a construção horizontal de proteção de direitos humanos virou pauta concreta na agenda internacional e a ONU passou a dedicar esforços para um consenso mais palpável quanto ao assunto.

Em 2003, a Subcomissão das Nações Unidas para os Direitos Humanos submeteu à avaliação da Comissão de Direitos Humanos as "Normas sobre a Responsabilidade de Empresas Transnacionais e outros Empreendimentos Privados com Relação aos Direitos Humanos”, que propunha normas de caráter imperativo e obrigações que se irradiariam direito internacional, no que tange à relação entre empresas e direitos humanos. ((GASPAR e BUSTILLO, 2013). O objetivo destas normas era explícito já no preâmbulo, ao estabelecer que apesar do Estado ser primariamente responsável pela realização dos direitos da cidadania, empresas privadas e transnacionais o são igualmente, reafirmando que as transnacionais cresceram em quantidade e também ampliaram sua influência nos contextos nacionais e internacionais; apesar de muitos dos sistemas nacionais não possuírem ainda muita autonomia no contexto que se criou a partir da mencionada expansão (NAÇÕES UNIDAS, 2003).

As normas, então, estabeleciam explicitamente que as empresas possuem obrigações e responsabilidades quando se trata de direitos humanos, como "promover, garantir o cumprimento, respeitar, garantir o respeito e proteger os direitos humanos reconhecidos na legislação tanto internacional quanto nacional” (NAÇÕES UNIDAS, 2003, tradução nossa). Ainda, o texto menciona expressamente o cabimento de obrigações positivas a serem impostas aos particulares nesta seara. Igualmente, determinava a adoção de ações afirmativas para nivelamento de qualquer desigualdade na área em que se encontrem instaladas as empresas, dentre outras iniciativas salutares.

Em seu tópico final, o documento estabelecia sua própria implementação. As próprias empresas seriam responsáveis por adotar medidas de implementação e funcionamento das 

uma abordagem emoldurada com conceitos habermasianos.

Normas, e submeteriam relatórios periódicos para fiscalização constante, sem excluí-las do monitoramento periódica pela ONU, realizado com o auxílio de ONGs, ou como resultado de queixas sobre violações. Ainda, as empresas deveriam realizar avaliações periódicas para avaliar seu impacto nos direitos humanos, além de reparar quaisquer danos causados pela não observação das Normas. Por fim, destaca-se que pelo seu cárter vinculante, estas poderiam ser aplicadas por tribunais nacionais ou internacionais, submetendo empresas também aos sistemas de proteção dos direitos humanos existentes no cenário internacional (GASPAR e BUSTILLO, 2013), o que seria absolutamente revolucionário no cenário atual.

O documento acima descrito, submetido à votação, não conseguiu aprovação pela Comissão de Direitos Humanos (ONU), sob justificativa de que não possuíam base legal, e a Subcomissão redatora não deveria preocupar-se com a regulamentação narrada. (NAÇÕES UNIDAS, 2003). Em verdade, o projeto não foi bem recebido por certo número de Estados, nem por organizações ligadas ao empresariado (à exemplo da Câmara de Comércio Internacional) (BILCHITZ, 2010). O lobby dirigido por grupos empresariais no processo (FEENEY, 2009, p.180) certamente conseguiu exercer maior influência (na acepção habermasiana do termo). Especula-se o insucesso do projeto deu-se pelo rigor das Normas, que atribuíam sérias obrigações, até mesmo de cunho positivo, às empresas. O acontecido estampa a ressalva ao modelo de iniciativa externa, como exposto por Cobb, Ross e Ross (1971), que:

(...) aplica-se à situação na qual um grupo se encontra fora da estrutura governamental: 1) articula uma demanda, 2) tenta propagar em outros grupos da população o interesse nessa questão a fim de ganhar espaço na agenda pública, o que permite, 3) uma pressão suficiente nos que têm poder de decisão, obrigando-os a inscrever a matéria na agenda formal, para que seja tratada seriamente.(...). Entretanto, o fato de ter adquirido status de uma agenda formal não significa necessariamente que a decisão final das autoridades ou que a atual política de implementação corresponderá às pretensões do grupo que formulara a demanda” (apud Habermas, 1997, p. 114, grifo nosso).

Em 2005, o tema voltou à pauta das Nações Unidas, sendo nomeado como Representante Especial, para averiguar pontos acerca de empresas e direitos humanos, o Prof. John Ruggie, que, durante seu mandato, elaborou um célebre relatório que restou conhecido 
como "marco Ruggie”, base para os "Princípios-orientadores das Nações Unidas acerca de empresas e direitos humanos: quadro sobre "proteger, respeitar e remediar” (GASPAR e BUSTILLO, 2013). Ele conduziu projetos de pesquisa, e realizou consultorias com 14 multistakeholders (líderes setoriais) de todos os continentes, produzindo inúmeros documentos essências para o panorama traçado no relatório em questão (NAÇÕES UNIDAS 2008, p.3).

Por fim, em 2011, o Conselho de Direitos Humanos logrou a aprovação dos “princípios-orientadores” pelos quais se implantaria o framework apresentado no relatório de Ruggie em 2008. Segundo estes princípios, as empresas somente seriam responsáveis por respeitar direitos humanos, evitando danos (NAÇÕES UNIDAS 2011, p.13). A finalidade dos princípios, não dotados de força vinculante seria atuar como um guia prático de atuação. Ruggie encerrou seu mandato com uma proposta minimalista:

A aprovação dos Princípios-orientadores, apenas, não trará um término aos desafios de empresas e direitos humanos. Mas marcará o fim de um começo: estabelece uma plataforma global de ação comum, na qual progresso cumulativo poderá se construir, passo-a-passo (...) (NAÇÕES UNIDAS, 2011 p. 5, tradução nossa).

Assim os principais autores do tema tratado seguem ressaltando que os princípios representam o fracasso de um plano e a vitória de interesses corporativos (BERRÓN, 2014, p.129) com o foco destes na criação de uma obrigação positiva para os Estados e não para as empresas (LOVE, 2014, p. 110).

Este processo, contudo, não se encerra com tais acontecimentos. A discussão continua em voga nas associações e organizações não governamentais que compõe a esfera pública, nacional e internacional. Ressalta-se, nesse modelo habermasiano, a importância da influência dessas mencionadas organizações que institucionalizam o discurso periférico levando-a para agenda do sistema político, exercendo sua pressão, na convencional luta por influência nesse sistema. Nesse sentido, Accioly destaca a atuação das organizações não governamentais no sistema político internacional, apontando que as ONGs transformam o cenário das organizações internacionais tradicionais com seus protestos e "ruído surdo", mas também com modos muito mais eficientes atualmente, de forma organizada, servindo como canais, caminhos possíveis, para veicular anseios da sociedade civil internacional, tendo demonstrado uma capacidade inovadora e crescente de poder de pressão sobre estados e sobre os modelos de gestão das organizações internacionais intergovernamentais (2011, p. 486). O mesmo autor sintetiza: 
Como dito, o mundo mudou consideravelmente e seus ferramentas de regulação e de ordenação têm de ser feitas de modo consentâneo à realidade em que se inscrevem. Mas não serão os estados a empreender tais mutações no direito internacional pós-moderno, pois o dinamismo na renovação do direito internacional, no contexto pós-moderno, tem vindo dos agentes não estatais no plano internacional [...]. (ACCIOLY, 2011, p. 487).

\section{Conclusão}

Como fora possível observar há um profundo vínculo da afirmação da dignidade humana, com os direitos humanos, os quais são frutos de lutas sociais. Porém, não há um consenso regulador, no tema, protetivo dos direitos humanos. Tal consenso encontra-se distante, principalmente, no que tange à conquista de um marco normativo e vinculante, que possa ter impactos efetivos, na realização dos direitos humanos.

Os conceitos habermasianos de esfera pública e sociedade civil, bem como o modelo de circulação de poder apresentado pelo autor, são essenciais para a elucidação do tema. Os documentos citados emanados de ONGs e instituições da sociedade civil ilustram as demandas atuais pela definição de obrigações mais amplas e até de caráter positivo para empresas, com relação aos direitos humanos. A sociedade civil e suas instituições, assim como os movimentos que atuam na esfera pública se mostram de grande importância para se levar a pauta à agenda do sistema político, assim como se mostram relevantes para fiscalização da atuação das empresas, atentando para eventuais violações e compilando casos, como no documento enviado ao segundo ciclo revisional universal.

Contudo, mesmo com a voz ativa desses atores na esfera pública internacional, as instituições econômicas, empresas e outros órgãos que possuem interesse na manutenção da situação atual, têm atuado com certo peso na equação, resultando que os avanços no assunto foram absolutamente minimalistas, resultando em criticismo por parte dos defensores da regulamentação da pauta, defensores dos direitos humanos. Isso porque, o marco Ruggie e os conseguintes princípios, como parece admitir o próprio representante especial, fez enormes concessões aos sistemas funcionais econômicos, não alcançando um status normativo.

Ainda assim, tais esforços foram vitoriosos em colocar o assunto na agenda internacional, em fomentar as discussões e pesquisas acerca do assunto, passo essencial para construção do consenso acerca da regulamentação da atuação de empresas quanto aos direitos humanos.

Frise-se que, diante dos princípios orientadores de Ruggie, foi estabelecido que apesar da responsabilidade primária do Estado pela proteção dos direitos humanos, as empresas e transnacionais igualmente possuem tal responsabilidade e precisam respeitar os ditames da Declaração Universal de Direitos Humanos e a tutela internacional desses direitos em geral.

A relação entre empresas e direitos humanos há de ser balanceada com muita cautela, de modo a minimizar-se quaisquer danos a ambos os polos, o que poderá ser alcançado por meio de regulamentações estatais que sejam conscientes dos variados aspectos presentes no tema. 
É preciso apontar, contudo que, assim como no contexto internacional, o caminho a ser trilhado para uma efetiva proteção e promoção dos direitos humanos é longo, uma vez que os esforços são ainda tímidos.

Conclui-se, desta maneira, que as preocupações daqueles que defendem os direitos humanos ainda subsistem no tocante à pauta tema deste artigo. O debate internacional e o processo de construção de consenso, em instrumentos com força vinculativa, já pautado, faz-se de suma importância, ecoando nas estruturas da esfera púbica habermaseana e batendo às portas do sistema político, influenciando, assim, os processos de decisão em organizações internacionais.

\section{Referências}

ACCIOLY, Hildebrando; SILVA, G. E. do Nascimento; CASELLA; Paulo Borba. Manual de Direito Internacional Público. 19. ed. São Paulo: Saraiva, 2011.

BERRÓN, Gustavo. Poder econômico, democracia e direitos humanos: um novo debate internacional sobre direitos humanos e empresas. Revista Sur, V. 11, n. 20, 2014. Disponível

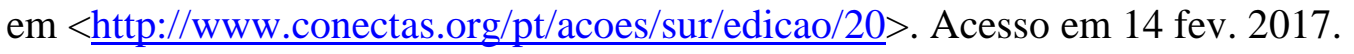

BILCHITZ, David. OMarco Ruggie: Uma Proposta Adequada para as Obrigações de Direitos Humanos das Empresas? Disponível em: $<$ http://www.surjournal.org/conteudos/getArtigo12.php?artigo=12,artigo_10.htm $>$ Acesso em: 12 mar. 2017.

BLOOMER, Phil. Os Direitos Humanos São uma ferramenta eficaz para a mudança social? Uma perspectiva sobre direitos humanos e empresas. Revista Sur, V. 11, n. 20, 2014. Disponível em <http://www.conectas.org/pt/acoes/sur/edicao/20 > . Acesso em 14 fev. 2017.

BRASIL. Constituição Federal da República Federativa do Brasil (1988). Disponível em: $<$ http://www.planalto.gov.br/ccivil_03/constituicao/constituicaocompilado.htm>. Acesso em 10 mar. 2017.

CALIARI, Aldo. Comércio, investimento, financiamento e direitos humanos: avaliação e estratégia. Disponível em:

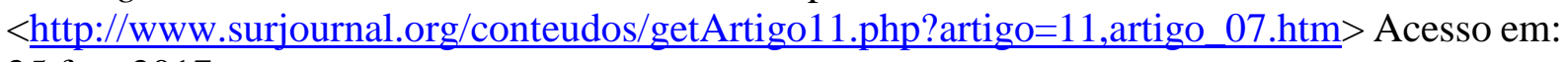
25 fev. 2017 
COMISSÃO INTERNACIONAL DE JURISTAS. Access to Justice: Human Rights Abuses Involving Corporations- Brazil (executive summary). Disponível em: $<$ http://www.conectas.org/arquivos/Brasil\%20ExecSumm-ElecDist(1).pdf $>$ Acesso em 04 abr. 2017.

CONECTAS DIREITOS HUMANOS; ÁGERE; INSTITUTO MAIS DEMOCRACIA; JUSTIÇA GLOBAL; PLATAFORMA BNDS. Brazilian obligations to address human rights violations perpetrated by companies. Disponível em: $<\underline{\text { http://www.conectas.org/arquivos/SubmissionUPRBrazil_BusinessandHR_Conectasanpartn }}$ ers.pdf> Acesso em: 25 mai. 2017

FEENEY, Patricia. A luta por responsabilidade das empresas no âmbito das nações unidas e o futuro da agenda de advocacy. Disponível em: <http://www.surjournal.org/eng/conteudos/pdf/11/08.pdf> Acesso em: 12 fev. 2017.

FÓRUM DA SOCIEDADE CIVIL. Civil Society Forum Declaration to UNCTAD XI.

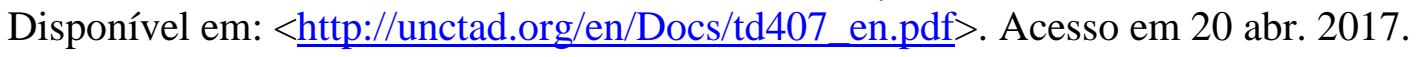

GASPAR, Renata Álvares; BUSTILO, Luísa Nascimento. Imposição de obrigações positivas a empresas e violações de Direitos Humanos: efeitos horizontais. Direito \& Paz, v. 2, 2013.

HABERMAS, Jürgen. Direito e democracia: entre facticidade e validade. Rio de Janeiro: Tempo Brasileiro, 1997.

HABERMAS, Jürgen. Entre naturalismo e religião: estudos filosóficos. Rio de Janeiro: Tempo Brasileiro, 2007

HABERMAS, Jürgen. Sobre a constituição da Europa: um ensaio. 1. ed. São Paulo: Unesp, 2012.

LOVE, Janet. Estaríamos despolitizando o poder econômico? A deliberada irresponsabilidade corporativa e a resposta burocrática dos defensores de direitos humanos. Revista Sur, V. 11, n. 20, 2014. Disponível em <http://www.conectas.org/pt/acoes/sur/edicao/20>. Acesso em 14 fev. 2017.

NAÇÕES UNIDAS. Conselho de Direitos Humanos. Guiding Principles on Business and Human Rights: Implementing the United Nations "Protect, Respect and Remedy" Framework. Disponível em: <http://www.business-humanrights.org/media/documents/ruggie/ruggieguiding-principles-21-mar-2011.pdf> Acesso em: 20 mar. 2017

Conselho Econômico e Social, Sub-Comissão para Promoção e Proteção de Direitos Humanos. Norms on the Responsabilities of Transnational Corporations and Other Business Enterprises with Regard to Human Rights. Disponível em: 
<http://www.unhchr.ch/huridocda/huridoca.nsf/(Symbol)/E.CN.4.Sub.2.2003.12.Rev.2.En> Acesso em 15 mar. 2017

Conselho de Direitos Humanos. Protect, Respect, and Remedy: A Framework for Business and Human Rights. Disponível em: <http://www.reports-and-materials.org/Ruggiereport-7-Apr-2008.pdf> Acesso em: 10 mar. 2017.

PIOVESAN, Flávia. Direitos Humanos e o Direito Constitucional Internacional. $13^{\mathrm{a}}$ ed. São Paulo: Saraiva, 2012.

RESENDE, Gilka; MENDES, Thiago. Atingidos pela Chevron no Equador cobram reparação de danos ambientais, sociais e culturais na Justiça brasileira. Disponível em: $<$ http://fase.org.br/pt/informe-se/noticias/atingidos-pela-chevron-no-equador-cobramreparacao-de-danos-ambientais-sociais-e-culturais-na-justica-brasileira/> Acesso em 12 fev. $\underline{2017}$

SARLET, Ingo Wolfgang. A eficácia dos fundamentais: uma teoria Geral dos Direitos Fundamentais na Perspectiva Constitucional. 10a ed. Porto Alegre: Livraria do Advogado, 2009.

SILVA, José Afonso da. Curso de direito constitucional positivo. 34. ed. São Paulo: Malheiros, 2011.

SILVA, Virgílio Afonso da. A constitucionalização do Direito: os direitos fundamentais nas relações entre particulares.1 $1^{\mathrm{a} e d . ~ S a ̃ o ~ P a u l o: ~ M a l h e i r o s ~ E d i t o r e s ~ L T D A, ~} 2011$.

VALADÉS, Diego. La protección de los derechos fundamentales frente a particulares.

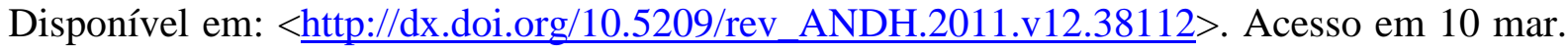
2017. 